\title{
Isolation and Stimulation of Peritoneal Macrophages with Apoptotic Jurkat Cells to Produce IL-10 \\ Mei Song ${ }^{1}$ and Xiaojing $\mathrm{Ma}^{1,2, *}$
}

\begin{abstract}
1Department of Microbiology and Immunology, Weill Cornell Medicine, New York, USA; ${ }^{2}$ Sheng Yushou Center of Cell Biology and Immunology, School of Life Science and Biotechnology, Shanghai Jiao Tong University, Shanghai, China

*For correspondence: xim2002@med.cornell.edu
\end{abstract}

[Abstract] Clearance of apoptotic cells by macrophages is critical to ensuring cellular homeostasis and suppression of autoimmunity. Macrophage recognition of apoptotic cells triggers an anti-inflammatory response, which is mediated by the release of IL-10, TGF- $\beta$ etc. with concurrent inhibition of pro-inflammatory cytokines (such as TNFa, IL-12, IL-1ß). To characterize cytokine profile produced by macrophages during phagocytosis of apoptotic cells, we developed an effective, more physiologic system using isolated murine peritoneal macrophages and T-lymphocyte cell line Jurkat as a source of apoptotic cells. Apoptosis of Jurkat cells is induced with staurosporine, a protein kinase C (PKC) inhibitor and detected by Annexin V/propidium iodide staining. This in vitro assay demonstrates that murine peritoneal macrophages produce large amounts of IL-10 following exposure to apoptotic Jurkat cells.

Keywords: Apoptosis, Macrophage, Jurkat, IL-10, Phagocytosis

[Background] Production of IL-10, a major immunoregulatory cytokine, by phagocytes during clearance of apoptotic cells is critical to ensuring cellular homeostasis and suppression of autoimmunity (Chung et al., 2007). Little is known about the regulatory mechanisms in this fundamental process. To elucidate the molecular mechanisms involved in the regulation of IL-10 gene expression in macrophages upon interaction with apoptotic cells, we developed this protocol to explore key regulators of IL-10 production induced by apoptotic cells.

\section{Materials and Reagents}

1. 24-well plate (Corning, catalog number: 3563847)

2. T-75 flask (Corning, catalog number: 431464)

3. Falcon ${ }^{\circledR} 50 \mathrm{ml} \mathrm{High} \mathrm{Clarity} \mathrm{PP} \mathrm{Centrifuge} \mathrm{Tube} \mathrm{(Corning,} \mathrm{catalog} \mathrm{number:} \mathrm{352070)}$

4. Posi-Click $1.7 \mathrm{ml}$ microcentrifuge tube (Denville, catalog number: C2170)

5. 10-ml syringe (BD, catalog number: 309695$)$

6. $25 \mathrm{G}$ and $18 \mathrm{G}$ needles (BD)

7. C57BL/6 mice (6-8 weeks old)

8. Cell line: Jurkat, Clone E6-1 (ATCC, catalog number: TIB-152) 
9. Fetal Bovine Serum (Thermo Fisher, catalog number: 16000)

10. RPMI 1640 Medium, GlutaMAX ${ }^{\mathrm{TM}}$ Supplement, and HEPES (Thermo Fisher, catalog number: 72400)

11. Penicillin-Streptomycin (10,000 U/ml) (Thermo Fisher, catalog number: 15140$)$

12. GlutaMAXTM Supplement (Thermo Fisher, catalog number: 35050)

13. Staurosporine (Sigma-Aldrich, catalog number: 19-123)

14. DPBS, no calcium, no magnesium (Thermo Fisher, catalog number: 14190)

15. FITC Annexin V Apoptosis Detection Kit I (BD Pharmingen, catalog number: 556547)

16. Mouse IL-10 ELISA Set (BD, catalog number: 565252)

17. BD BBL Dehydrated Culture Media (Fisher Scientific, catalog number: 211716)

18. Dimethyl sulfoxide (Sigma-Aldrich, catalog number: D2560)

19. $70 \%$ Ethanol

20. Complete media for Jurkat T cells (see Recipe 1)

21. $3 \%(w / v)$ Brewer thioglycollate medium (see Recipe 2)

22. $1 \times$ Binding buffer(see Recipe 3 )

23. RPMI-1640-10 (see Recipe 4)

24. $0.5 \mathrm{mg} / \mathrm{ml}$ Staurosporine (1,000x stock) (see Recipe 5)

\section{Equipment}

1. Tissue culture hood (biosafety cabinet, Forma Scientific, model: 1284)

2. $37^{\circ} \mathrm{C}, 5 \% \mathrm{CO}_{2}$ humidified incubator (Thermo Forma, model: 3110 Series II)

3. Centrifuge (Thermo Scientific, ST8 Benchtop Centrifuge)

4. Optical microscopy (Olympus, CK30)

5. Flow cytometer (BD,FACSCalibur)

6. Sterile Surgical Scissors (Miltex, MH5-302)

7. Hemacytometer (Hausser Scientific, catalog number: 02-671-5)

8. Autoclave

\section{Software}

1. FlowJo software (7.6.1)

2. GraphPad Prism

\section{Procedure}

A. Subculturing Jurkat cell Line

1. Transfer growing cells from $\mathrm{T}-75$ flask to a $50 \mathrm{ml}$ centrifuge tube followed by centrifugation at $300 \times \mathrm{g}$ for $5 \mathrm{~min}$ at room temperature. 
2. Remove and discard the supernatant (old growth medium from above the cell pellet) and resuspend the cell pellet with fresh complete growth medium.

3. Add a proper volume of Jurkat cell suspension to a new T-75 flask containing $15 \mathrm{ml}$ of complete growth medium with approximately $10^{5}$ viable cells/flask and subculture every 3-4 days.

4. Place the culture flask in a $37^{\circ} \mathrm{C}, 5 \% \mathrm{CO}_{2}$ humidified incubator.

B. Inducing apoptosis of Jurkat cells

1. Harvest exponentially growing Jurkat cells (initial concentration of $2 \times 10^{5} \mathrm{cells} / \mathrm{ml}$, and final concentration of $6-8 \times 10^{5}$ cells $/ \mathrm{ml}$, usually two days after seeding) by centrifugation at $300 \times \mathrm{g}$ for $5 \mathrm{~min}$ (same procedure for Jurkat cells subculturing/harvesting/washing).

2. Resuspend cells in fresh medium to a final concentration of $1 \times 10^{6} \mathrm{cell} / \mathrm{s} / \mathrm{ml}$ and seed into a new T-75 flask. Another flask will be used as the negative control for non-induced cells (note that there would be two groups, one for apoptosis, and the other for non-apoptosis control group).

3. Add staurosporine into Jurkat cell culture with a final concentration of $0.5 \mu \mathrm{g} / \mathrm{ml}$, and incubate in a $37{ }^{\circ} \mathrm{C}, 5 \% \mathrm{CO}_{2}$ humidified incubator for $6-8 \mathrm{~h}$. Add the same volume of DMSO into control Jurkat T cell culture.

4. Harvest cells for staining at different times (i.e., 3, 6, $12 \mathrm{~h}$ ) after the addition of staurosporin/DMSO by transferring $2 \mathrm{ml}$ of cell culture medium into a fresh Falcon tube and centrifugation. Keep culturing the rest of cells in T-75 flask in a $37{ }^{\circ} \mathrm{C}, 5 \% \mathrm{CO}_{2}$ humidified incubator.

C. Detection apoptosis of Jurkat cells with FITC Annexin V Apoptosis Detection Kit

1. Wash harvested staurosporine-treated Jurkat cells twice with cold DPBS to stop the reaction.

2. Resuspend cells in $1 \times$ Binding buffer at a concentration of $5 \times 10^{6}$ cells $/ \mathrm{ml}$.

3. Transfer $100 \mu \mathrm{l}$ of the solution $\left(\sim 5 \times 10^{5}\right.$ cells $)$ to a new $1.7 \mathrm{ml}$ microcentrifuge tube.

4. Add $2 \mu \mathrm{l}$ of FITC Annexin V and $2 \mu \mathrm{l}$ of PI, gently vortex the cells and incubate for $15 \mathrm{~min}$ at room temperature or $30 \mathrm{~min}$ on ice, protecting from light under either condition.

5. Add $400 \mu \mathrm{l}$ of $1 \times$ Binding buffer to each tube, wash twice (centrifugation at $400 \times \mathrm{g}$ for $5 \mathrm{~min}$ ) and analyze by flow cytometer within $1 \mathrm{~h}$ (Figure 1). 

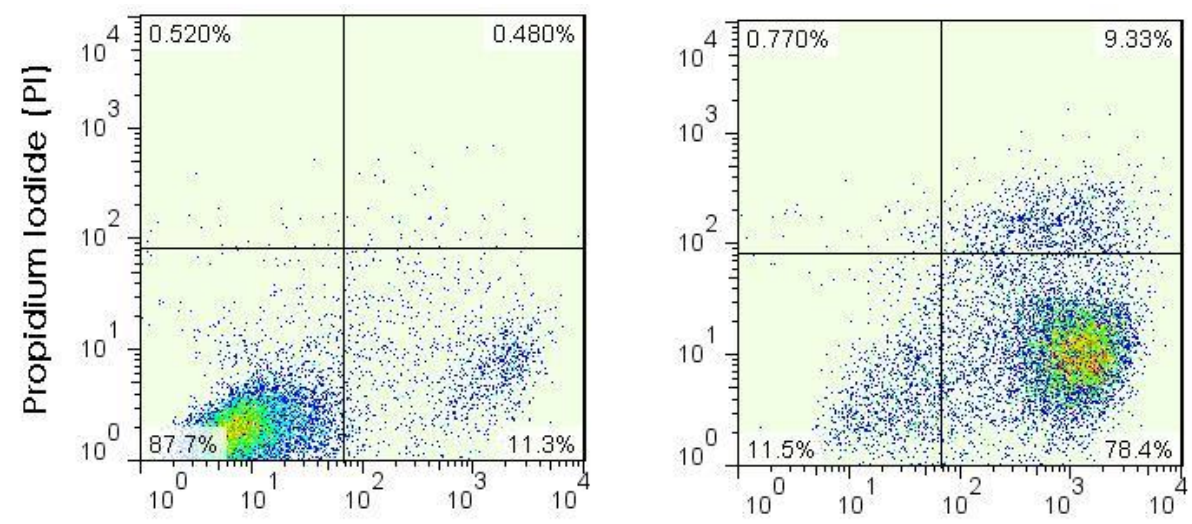

Figure 1. Apoptosis of Jurkat cells induced by staurosporine. After $6 \mathrm{~h}$-induction, the percentage of early- and late-apoptotic cells was quantified by flow cytometry analysis with Annexin $\mathrm{V}$ and propidium iodide $(\mathrm{PI})$ staining. The numbers indicate the percentage of subpopulations.

D. Intraperitoneal injection of thioglycollate

1. Fill a $10-\mathrm{ml}$ syringe with $3 \%$ Brewer thioglycollate medium with a $25 \mathrm{G}$ needle.

2. Inject $2 \mathrm{ml}$ of solution per mouse into the peritoneal cavity, allowing inflammatory response to proceed for 4 days.

E. Harvest and culture thioglycollate-elicited peritoneal macrophages

1. Euthanize mouse with $\mathrm{CO}_{2}$ and clean abdomen with $70 \%$ ethanol.

2. Make a small incision along the midline with sterile scissors and retract the abdominal skin manually to expose the transparent peritoneal wall.

3. Fill a 10-ml syringe with $9 \mathrm{ml}$ of DPBS or RPMI-1640-10 (Recipe 4), then inject harvest medium with a $25-\mathrm{G}$ needle into the peritoneal cavity.

4. Massage abdomen for $\sim 30 \mathrm{~s}$ and recover peritoneal fluid without puncturing any abdominal organs using a $10 \mathrm{ml}$ syringe with $18 \mathrm{G}$ needle ( $~ 8 \mathrm{ml}$ fluid could be recovered from per mouse) (Video 1). 


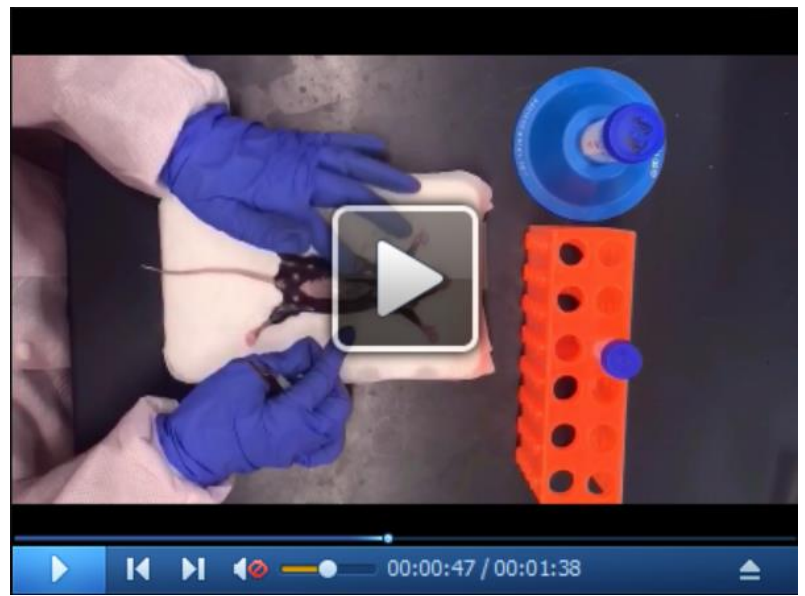

Video 1. Harvest peritoneal macrophages (Steps E2-E4)

5. Remove the needle from the syringe and dispense peritoneal fluid into a $15 \mathrm{ml}$ Centrifuge tube on ice (Cells should be kept cool throughout the procedure).

6. Centrifuge the peritoneal cells in a refrigerated centrifuge for $5 \mathrm{~min}$ at $400 \times \mathrm{g}$. Discard supernatant and resuspend the cell pellet in $5 \mathrm{ml}$ of RPMI-1640-10 medium by gently pipetting up and down.

7. Count cells using hemacytometer (with 1:10 dilution by mixing $100 \mu \mathrm{l}$ of cell suspension with $900 \mu \mathrm{l}$ of trypan blue).

8. Adjust cell concentration with RPMI-1640-10 and seed into 24 -well plate at $5 \times 10^{5}$ cells/well (500 $\mu \mathrm{l}$ of medium per well).

9. Cells are allowed to adhere to the plate by culturing for $2-3 \mathrm{~h}$ in $37{ }^{\circ} \mathrm{C}, 5 \% \mathrm{CO}_{2}$ humidified incubator. Non-adherent cells are removed by gently washing three times with $1 \mathrm{ml}$ of warmed PBS (Remaining cells should be greater than 90\% macrophages).

F. Stimulate peritoneal macrophages with apoptotic Jurkat cells

1. After overnight culture, media for peritoneal macrophages are changed with $500 \mu \mathrm{l}$ of RPMI-1640 without FBS.

2. Add $100 \mu \mathrm{l}$ of induced and evaluated apoptotic Jurkat cells (suspended in RPMI-6140 without FBS, with a concentration of $25 \times 10^{6} \mathrm{cells} / \mathrm{ml}$ ) into macrophage cultures at a 5:1 ratio.

3. Harvest cell culture supernatants at $8 \mathrm{~h}, 16 \mathrm{~h}$ after apoptotic cell challenge.

4. Centrifuge harvested samples in a refrigerated centrifuge for $10 \mathrm{~min}$ at $500 \times \mathrm{g}$, and then carefully transfer cleared supernatant $(\sim 600 \mu$ l) to a new tube without disturbing cell pellet.

G. Detection of IL-10 production by ELISA (Figure 2) 


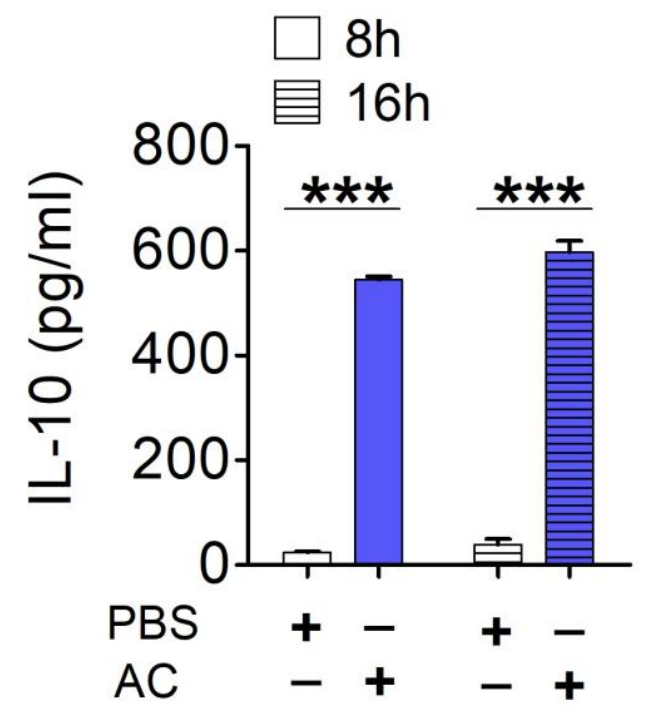

Figure 2. Macrophages produce IL-10 in response to apoptotic cells. $5 \times 10^{5}$ thioglycollate-elicited peritoneal macrophages were stimulated with apoptotic Jurkat cells (AC) (5:1 ratio of $A C$ to macrophages) for indicated times and analyzed for IL-10 production.

\section{Data analysis}

1. Analysis was performed using FlowJo software (7.6.1). Average three independent replicates to obtain a single read to each sample.

2. To evaluate apoptosis of Jurkat cells, use unstained negative control to determine the absolute boundaries for both Annexin V-FITC and propidium iodide (PI) positive cells. Be sure to compare data generated with control cells (DMSO treated cells) to that of the unstained negative control.

3. For ELISA, subtract the value of blank sample to avoid background reads.

4. Mean values and standard deviation (S.D.) were used as descriptive statistics. Comparisons between two groups were performed using an unpaired two-tailed Student's $t$-test $(P<0.05$ was considered statistically significant).

\section{Recipes}

1. Complete media for Jurkat cells

RPMI 1640 Medium, GlutaMAX ${ }^{\mathrm{TM}}$ Supplement, and HEPES (450 ml)

$50 \mathrm{ml}(10 \%)$ Fetal Bovine Serum

$5 \mathrm{ml}$ (100x) Penicillin-Streptomycin

$5 \mathrm{ml}$ (100x) GlutaMAX ${ }^{\mathrm{TM}}$ Supplement

2. $3 \%(w / v)$ Brewer thioglycollate medium 
a. Suspend $30 \mathrm{~g}$ of BD BBL Dehydrated Culture Media (Fisher scientific) in 1,000 $\mathrm{ml}$ of distilled water and autoclave to sterilize

b. After cooling, aliquot to $50 \mathrm{ml}$ Centrifuge Tubes, and could be stored in the dark at room temperature for 3 months

3. $1 \times$ Binding buffer

10x Annexin V Binding Buffer (component no. 51-66121E): 0.1 M HEPES/NaOH (pH 7.4), 1.4 $\mathrm{M} \mathrm{NaCl}, 25 \mathrm{mM} \mathrm{CaCl} 2$

For a $1 \mathrm{x}$ working solution, dilute 1 part of the $10 \mathrm{x}$ Annexin $\mathrm{V}$ Binding Buffer to 9 parts of distilled water

Note: $1 x$ Binding buffer should be freshly prepared.

4. RPMI-1640-10

To prepare RPMI-1640-10, additionally supplement RPMI-1640 medium with $10 \%(\mathrm{v} / \mathrm{v})$ fetal bovine serum

5. $\quad 0.5 \mathrm{mg} / \mathrm{ml}$ Staurosporine $(1,000 \mathrm{x}$ stock)

a. Resolve $200 \mu \mathrm{g}$ of Staurosporine (Sigma-Aldrich) in $400 \mu \mathrm{l}$ Dimethyl sulfoxide (Sigma-Aldrich)

b. Aliquot and store at $-20^{\circ} \mathrm{C}$ and thaw an aliquot before each use

\section{Acknowledgments}

This work was supported by an NIH grant (1R21Al110815) to X.M. This protocol was adapted from Chung EY et al. (2007).

\section{Competing interests}

The authors declare no conflicts of interest.

\section{References}

1. Chung, E. Y., Liu, J., Homma, Y., Zhang, Y., Brendolan, A., Saggese, M., Han, J., Silverstein, R., Selleri, L. and Ma, X. (2007). Interleukin-10 expression in macrophages during phagocytosis of apoptotic cells is mediated by homeodomain proteins Pbx1 and Prep-1. Immunity 27(6): 952-964. 